\title{
Changes in Chromatin Structure along Aging
}

\author{
Alberto da Silva Moraes \\ Institute of Biomedical Sciences, Federal University of Uberlandia, Uberlandia, MG, Brazil \\ *Corresponding author: Alberto S Moraes, Cytology, Histology, and Embryology Section, Institute of Biomedical Sciences, Federal University of Uberlandia, Av Para, \\ 1720, Building 2B, 2nd floor, Bairro Umuarama, Uberlandia, Minas, Gerais, 38400-902, Brazil, Tel: +55 34 3218-2240; Fax: +55 34 3218-2240; E-mail: \\ albertomoraes@icbim.ufu.br
}

Rec date: Mar 17, 2014; Acc date: May 01, 2014; Pub date: May 03, 2014

Copyright: (c) 2014 Moraes AS. This is an open-access article distributed under the terms of the Creative Commons Attribution License, which permits unrestricted use, distribution, and reproduction in any medium, provided the original author and source are credited.

\begin{abstract}
In a world with an increasing aging population, a proper understanding of the biology of the aging process could be of economic and social significance for governments, in order to guarantee a long but productive life for the elderly. In this regard, studies about the relationship between changes in chromatin organization and aging are pivotal, since it has been widely accepted that the aging process can be genetically driven. Several studies have shown that aging is associated with changes in gene expression and chromatin structure, and that in many cases, including diseases; such phenotypes can be pharmacologically altered in order to reestablish homeostasis. Therefore, the objective of this review was to analyze what has been published in this subject from a historical perspective, and to discuss what can be concluded from those results with its impact in human health.
\end{abstract}

Keywords: Aging; Chromatin; Epigenetics

\section{Background}

Life expectancy is growing steadily all over the world, mainly in almost every country, as a result of good health policies and socioeconomic development. According to data from the World Health Organization (http://www.who.int/kobe_centre/ageing/en/), by 2050 , about 400 million people in the world are expected to be 80 years or more. In Japan, for example, by this time, almost a quarter of total population is going to be older than 80 years.

In a brilliant graphic posted by Sally Squires and Brenna Maloney in the 2006's December 5th edition of the Washington Post, Todd Linderman summarized how several tissues and organs of the human body age. It includes detrimental changes in skin, muscles, bones, joints and cartilages, senses, heart, neural tissue, stomach, as well as body strength and height. Along cellular aging, several biochemical changes lead to the loss of function and proliverative capacity, arrest of the cell cycle and replicative senescence. The process of cellular senescence contributes to the organismal aging, due to the decrease in proliferative capacity and consequent tissue loss of function [1]. Therefore, aging is characterized as one of the main risk factors to the onset of human diseases like neurodegenerative and cardiovascular diseases, while the abnormal aging of tissues generally results in cancer $[2,3]$. It's not surprising thus, that aging has been increasingly considered an important public health issue for governments all around the world. Therefore, it is necessary to guarantee that all people ages healthy and be able to maintain a normal and active life longer than our ancestors did.

No one is expecting to live forever, but certainly, live longer with a younger body can be very attractive for anyone. The only way to achieve this, if you are not naturally gifted with a long and healthy life, is first to understand all the cellular mechanisms behind the aging process, and then, how we can modulate them, in order to postpone aging or, at least, avoid all the age-related diseases that take place in older people. This concept started a run that ended in a huge amount of published articles in the field. An analysis of published articles indexed in the Web of Science database using the search descriptor "human aging" brought about 166 thousand results. Almost 50\% of them have been published solely after 2005. It shows the increasing interest in studying human aging due to the impact it has on our lives and several sectors of our societies, comprised of a fast increasing aged population.

Holger P. von Hahn from the Institute of Experimental Gerontology in Basel, Switzerland, was, on 60's, one of the first researchers to propose that the aging process could be genetically regulated [4]. Even before his work and until the present days, several theories have been created and debated in order to explain the aging process. Two groups arose: that of the social theories and that of the biological theories of aging. To see a very complete review on the biological theories of aging, please refer to the work of Linares et al. [5]. By that time, one of the main accepted biological theories of aging stated that cells could age because of reduced protein synthesis. According to von Hahn [4], this could be explained by three mechanisms: 1 . Loss of genes, by chromosomal breaks not only during mitosis; 2. Gene mutations (Theory of somatic mutations); 3. Failure of normal gene regulation. Giving more importance to the third mechanism, the author concluded that aging could be a genetically driven rather than a stochastic process, more related to the first two mechanisms. This gave birth to the endless search for changes in gene expression along aging in several tissues and organs in different models, from yeast to humans, also including fish, worms, and insects just to give a few examples. Nowadays, it is very well accepted that aging, rather than being only a stochastic event, is also a genetically driven phenomenon, and that it could be a consequence of altered gene expression profiles.

\section{Chromatin Structure and Function}

In cell biology there is a crosstalk between structure and function (for example, collagens and cytoskeletal proteins are fibrilar in nature and are, thus, adapted to resist mechanical stress, or the structure of phospholipids, which in an aqueous environment, naturally self- 
Page 2 of 6

assemble in phospholipids bilayers. This applies to genes as well, and besides of their primary structure (the genetic information behind the gene base sequence), gene expression can be controlled by the accessibility of their information by transcription factors and polymerases. This is due to the association of DNA with nuclear proteins, in a supramolecular entity called chromatin. Such structure is comprised of the entire genomic DNA wrapped around nuclear proteins called histones. These proteins are small arginine- and lysinerich basic proteins, whose interaction with DNA is based on hydrostatic forces between the positively charged lateral chains of argines and lysines on histones and the negatively charged phosphates on the DNA backbone. There are several types of histones, from which two of each histone $\mathrm{H} 2 \mathrm{~A}, \mathrm{H} 2 \mathrm{~B}, \mathrm{H} 3$, and $\mathrm{H} 4$, interact with each other to form a histone octamer. A DNA molecule thus wraps around this octamer between 1,75 and two turns (about 146 bp of DNA) except for a small fraction of the double helix that remains unwrapped and is called linker DNA (about $50 \mathrm{bp}$ ). This structural unit, called nucleosome, repeats endlessly until all the chromosome has been packed in a polynucleosome fiber. Thus, each chromosome in the nucleus consists of a single DNA molecule organized with histones and non-histone proteins in the form of a polynucleosome fiber, called chromatin [6,7]. A fifth histone type, called H1, binds to chromatin outside the nucleosomal core, and is associated with the regulation of chromatin packaging [8].

The structure of chromatin modulates gene expression. In a very simplistic way, chromatin can be found in two different forms. A very open, transcription permissive, and normally gene-rich form, known as euchromatin, which is more prone to degradation by nucleases, more accessible to transcription factors, and replicates early during $\mathrm{S}$ phase. On the other hand, most of the gene-poor regions, which replicates late in $\mathrm{S}$ phase, are poorly accessible by nuclear factors, generally rich in repetitive sequences, much more compact, and collectively known as heterochromatin [7]. Today, many authors just use the terms open and compact chromatin, rather than the eu- and heterochromatin concepts proposed by Heitz [9] to describe, respectively, active and inactive states of chromatin, in respect to their transcriptional activity. For a very complete review about chromatin structure and organization see [10].

\section{Aging is Associated with Changes in Chromatin Structure}

Since chromatin structure is responsible for modulation of gene activity, and considering that the aging process is genetically driven, it was natural to conclude that aging could be associated with changes in chromatin structure and composition. As we can see below, this relationship was extensively shown in several studies, as well it has been observed in cells from patients with aging syndromes $[11,12]$. This is supported also by the observation that changes in chromatin structure appear not only in cancer cells (where cancer is a typical aging-related disease) but also in cells obtained from "normal" epithelium taken several centimeters from the (colon) tumor [13].

One of the first attempts to link chromatin and aging came from studies back to 60's when it was shown that DNA composition does not change with age [14]. So, the age-related increased thermal stability observed in beef thymus chromatin was a consequence of increased nucleoprotein-DNA interaction, making this chromatin less readable by polymerases $[15,16]$. Latter, it was shown that such agedependent chromatin condensation could also be attributed to a shift on histone $\mathrm{H} 1$ types, possibly a conserved mechanism in all aging tissues [17], or an increased presence of disulfide bonds between nucleoproteins [18]. It is important to mention that $\mathrm{H} 1$ histones are normally required for the maintenance of chromatin organization along aging, and some aged models seems to have decreased levels of this protein [19]. Other studies, also evaluating the thermal stability of chromatin with age, found similar results in rat liver [20], being this property reversed by hepatectomy [21]. This means that age-related chromatin changes can be also associated with a reduced proliferative capacity, thus contributing to the aging and loss of function on tissues, which is also true for adult stem cell compartments [22]. Interestingly, in the liver, the reestablishment of the proliferative environment (as a consequence of hepatectomy), can also change chromatin structure back to a young phenotype. It cannot be excluded the possibility of the reduction in proliferative capacity might be associated with opposite changes in chromatin, as those observed in aged cultured human skin fibroblasts (i.e. chromatin with more single-stranded character, and thus more easily denaturable and prone to breakage) [23]. In fact, chromatin breaks were commonly observed in cells from patients with Xeroderma pigmentosum, an age accelerating disease [12]. Despite the fact increased levels of chromatin breaks were observed in mouse liver chromatin subjected to salt dissociation [24],such differences were not associated with changes in the amount of DNA-associated proteins, and thus chromatin packaging. Despite some proteomic studies have detected changes in nuclear proteins with age [25], it seems that histone proteins do not change along aging, at least not for neurons [26].

In all cases above described, a relationship between changes in chromatin structure and functional aspects in aged cells has been made, since the ability of this altered chromatin to function as a transcriptional template has decreased with age, at least in vitro. In fact, according to [27], cell senescence is characterized by a reduction of cell metabolism and a restriction on DNA transcription and proliferative capacity, being all of this associated with increased condensed chromatin. The reduction of template activity of chromatin was also found in aged normal female embryonic lung WI38 cells [28]. Contrarily, as it was observed in submandibular glands from rats [29], cultured aged skin fibroblasts [30], and mouse hepatocytes [31], chromatin unpackages with aging with a consequent increase in the template activity. Therefore, no generalizations can be made for different cell types in this respect. It is important to mention that, when homologous polymerase was used in the in vitro assays, no impairment of template activity was observed with age, but only when heterologous polymerase from E. coli was used [32]. Replicative activity of chromatin was also described as decreased in senescent cells [33], and was attributed to changes of DNA-protein interactions since no age-related differences in the activities of DNA polymerases have been found $[34,35]$.

Studies on chromatin accessibility to nucleases were proved to be good resources for the evaluation of chromatin structure. By using this approach, it was shown that bulk chromatin from old mouse or rat livers was less susceptible to nuclease digestion being, thus, more compact [36,37], with the same being true also for the satellite DNA [38]. Such chromatin condensation in old animals has been reversed by administration of steroid hormones [39]. Firstly Berkowitz et al. [40], and then Thakur et al. [41] showed that chromatin from cortical/ cerebellar neurons condensed with age. Again, this packaging was associated with increased protein-DNA interactions, and also with age-associated differential gene expression, thus corroborating, for another tissue, the results published earlier [15]. Interestingly, when nuclei extracted from the whole brain were subjected to the same 
Page 3 of 6

approach [35,36], no age-related difference was found, thus implying that, in the same tissue, we can find cells with no age-related alteration on chromatin structure or even some cells with a completely opposite phenotype (chromatin loosened with aging). It means that neurons from different regions of brain can have their own genetic programs according to their specific functions or localization, and therefore, could age differently from the others, showing diverse age-associated chromatin configurations. Other studies have found no age-related change in chromatin organization for whole brain, liver, kidney or heart tissue $[42,43]$, or chromatin unpackaging for mouse hepatocytes with aging [44], when subjected to nuclease digestion. It was argued that the non-dividing nature of these cells could be an explanation, since when aged skin fibroblasts were analyzed under the same approach, changes in chromatin organization were found (i.e. more spaced nucleosomes)[45]. From this variable results, it can be concluded that diverse chromatin configurations can be found in cells from aged donors, depending on the starting material, whole tissue or organ or specific cell types isolated from them.

Age-associated chromatin changes have also been observed in gametes, thus negatively affecting mammalian reproduction. For instance, age-related chromatin decondensation in oocytes have been shown to be associated with fertilization defects, like predisposition of oocytes to parthenogenetic activation without male pronucleus formation [46], and leading to decreased fertility [47], while sperm cells from aged donors are more vulnerable to oxidative damage due to an age-associated chromatin unpackaging $[48,49]$, and are rich in chromatin defects like decreased genome integrity, and gene mutations [50]. Again, data in literature are still conflicting, since others have found no evidence of age-related cellular alterations on sperm cells that could impair men's fertility [51].

Acid hydrolysis followed by staining using the Feulgen Reaction, a histochemical method specific for DNA, have also been used to study chromatin organization. Using image analysis and comparison of hydrolysis curves of Feulgen stained material it is possible to make assumptions about chromatin condensation levels. By using this approach, Myśliwski et al.. [52] found, similar to earlier results, that chromatin condenses with age in nuclei from rat liver. Additionally, they found that ploidy level did not influence this phenotype. This means that all liver population, irrespective of their ploidy status, ages the same, at least in relation to chromatin aging. Image analysis also revealed that aging is associated with changes in textural features in the chromatin of erythroid precursor cells, negatively impacting the hematopoietic properties of spleen on aged animals [53].

Increased chromatin packaging in old animals has several times been observed in the form of condensed regions called senescence associated heterochromatin foci (SAHF) [54]. These regions of heterochromatin accumulate along aging, even in cells with generalized chromatin unpackaging, thus leading to the theory that, instead of increased or decreased chromatin condensation, aging comes followed by heterochromatin redistribution [55].

An increase in adducts on DNA (e.g. loss of amino groups from cytosine and adenine, methylation of cytosines, and protein-DNA cross linkages) has been observed by Cutler [56]. Nowadays, it is well known that DNA can be modified epigenetically by methylation on specific bases, mainly cytosines in CpG islands, and that DNA methylation increases with age in several model organisms and humans [57,58]; mainly in bivalent chromatin domains (domains with both activating and inhibitory epigenetic marks), which generally comprises housekeeping and developmental genes [59]. Contrarily, primary cultures of human cells showed decreased DNA methylation associated with decreased chromatin condensation as cells age in culture and hit replicative senescence [60], thus implying that this subject is still controversial, and needs further investigation.

Changes of post-translational modifications of proteins, especially histones, which are one of the most important and studied epigenetic mechanisms, were also observed in aging models: core histone acetylation was observed to decrease with age $[61,62]$, along with the transcriptional potential of aged chromatin; although, increased $\mathrm{H} 1$ acetylation levels were observed in several mouse tissues along aging [63], concomitant with increased deamination. Contrarily to $[61,62]$, core histone acetylation was observed to increase in aged neurons from mice [64], and could be a reflex of decreased activity, concentration, or redistribution of SIRT1 or the NURD complex, both responsible for histone deacetylation [65,66], leading to increased genome instability and aging [67]. SIRT1 is a NAD+-dependent histone deacetylase, and it was shown that in human aged tissues there is a NAD+ depletion [68], thus explaining the enzyme reduced activity and accumulation of histone acetylation. Therefore, NAD+-dependent histone deacetylases (e.g. SIRT1) function as metabolic sensors, and nutritional interventions like caloric restriction, which increases the level of NAD+, can increase the activity not only of these proteins, but also of nuclear repair enzymes, such the poly(ADP-ribose) polymerase - PARP, thus increasing life span [68-70]. For a review on the role of histone deacetylases on aging, see the work of Guarente [71]. Furthermore, addition of methyl marks on key residues on histone tails comprise another important epigenetic mechanism of gene expression control, and both age-related accumulation [58], and loss $[64,72,73]$ of histone methyl marks associated with heterochromatin have been observed in several models. In the latter case, loss of repressive methyl marks on histone tails can lead to the activation of normally repressed genes, which is observed, for example, in some aging nephropathies, where there is abnormal activation of collagen genes, followed by tissue fibrosis and loss of function [74].

Post-translational modifications, mainly phosphorylation, of nonhistone chromosomal proteins were also viewed to be age-related [75]. Concluding, active or stochastic, several epigenetic events are associated with aging, and can be responsible for age-associated chromatin remodeling [55]. Age-related epigenetic changes have a very strong negative impact on adult stem cell function and proliferative capacity, thus leading to impaired tissue renewal and organismal aging $[22,76]$. In addition, tt has been observed that stem cells accumulate DNA double strand breaks (DSBs) with age, and that repair or misrepair of such regions leads to alterations on epigenetic marks with consequent transcription deregulation [77].

Telomere shortening has also been described as having a pivotal role in inducing genome instability, leading to an aged phenotype [78]. In almost all organisms with linear genomes, telomeres cannot be completely replicated after each cell division cycle, and shortens gradually. As long as they become too short, cell cycle is arrested and cells enter replicative senescence. The mechanism protects the organism from perpetuating cells after a lifetime exposure of their genomes to damage, which can lead e.g. to the development of cancer. However, the decreased ability of tissue renewal, due to diminished cellular proliferative potential, leads to an aged phenotype [79]. Paradoxically, the organism ages to avoid accumulation of genome defects, but it also ages because of accumulation of genomic defects. In this respect, genome defects, like DNA damage, are generally associated with cell aging, either being responsible to elicit alterations 
Page 4 of 6

in chromatin structure, or even as a result of altered chromatin structure [80].

\section{Concluding Remarks}

It is clear from the results summarized above that, irrespective of the big advance we experienced in the last 40 years about the relationship between aging, chromatin structure, and gene expression, much still needs to be done, since many of the available results are still contradictory, preliminary, or valid for only some cell types. Additionally, every study on this subject incurs in the same problem: a clear relationship between changes in chromatin structure and the aging process in a cellular level have been established, but we still do not know if the aging is a consequence of altered gene expression profiles, caused by changes in chromatin organization, or if this structural and functional changes are a product of the aging process itself. The only way to achieve this is to use aging models in which the age-related molecular changes are screened along a more comprehensive life interval, in order to find which comes first, molecular or phenotypic changes. Of course, for economic aspects and ethical issues on the use of laboratory animals, it is not an easy task to complete, and obviously, much of the questions that still need to be solved cannot be answered with in vitro studies.

\section{Acknowledgements}

Some works cited here are from my research group and have received financial support from the University's Research and Postgraduation Council, from Minas Gerais State Research Foundation (FAPEMIG), and from CAPES. I would like also to thank FAPEMIG for paying the publication costs. Some resources from Sao Paulo State Research Foundation (FAPESP), and also from the Brazilian National Council for Research and Development $(\mathrm{CNPq})$ have also been employed. This author apologizes with other authors whose works have not been cited here due to limitations of space.

\section{References}

1. Dimauro T, David G (2009) Chromatin modifications: the driving force of senescence and aging? Aging (Albany NY) 1: 182-190.

2. Feser J, Truong D, Das C, Carson JJ, Kieft J, et al. (2010) Elevated histone expression promotes life span extension. Mol Cell 39: 724-735.

3. Sikora E, Arendt T, Bennett M, Narita M (2011) Impact of cellular senescence signature on ageing research. Ageing Res Rev 10: 146-152.

4. von Hahn HP (1966) A model of "regulatory" aging of the cell at the gene level. J Gerontol 21: 291-294.

5. Linares JJG, Rossell NY, Fuentes MCP (2005) Review of biological hypotheses explaining aging. Anales de Psicología 21:323-327.

6. Klug A, Rhodes D, Smith J, Finch JT, Thomas JO (1980) A low resolution structure for the histone core of the nucleosome. Nature 287:509-516.

7. Woodcock CL, Dimitrov S (2001) Higher-order structure of chromatin and chromosomes. Curr Opin Genet Dev 11: 130-135.

8. Hizume K, Yoshimura SH, Takeyasu K (2005) Linker histone H1 per se can induce three-dimensional folding of chromatin fiber. Biochemistry 44: 12978-12989.

9. Heitz E (1928) Das heterochromatin der moose. I Jahrb Wiss Bot 69:762-818

10. Olins DE, Olins AL (2003) Chromatin history: our view from the bridge. Nat Rev Mol Cell Biol 4: 809-814.

11. Puvion-Dutilleul F, Macieira-Coelho A (1983) Aging dependent nucleolar and chromatin changes in cultivated fibroblasts. Cell Biol Int Rep 7: 61-71.
12. Puvion-Dutilleul F, Sarasin A (1989) Chromatin and nucleolar changes in Xeroderma pigmentosum cells resemble aging-related nuclear events. Mutat Res 219: 57-70.

13. Lukásová E, Kozubek S, Falk M, Kozubek M, Zaloudík J, et al. (2004) Topography of genetic loci in the nuclei of cells of colorectal carcinoma and adjacent tissue of colonic epithelium. Chromosoma 112: 221-230.

14. Pyhtila MJ, Sherman FG (1967) Age related changes in chromatin and its components. Fed Proc 26:667.

15. Pyhtilä MJ, Sherman FG (1968) Age-associated studies on thermal stability and template effectiveness of DNA and nucleoproteins from beef thymus. Biochem Biophys Res Commun 31: 340-344.

16. Ungerullmann C, Modak SP (1979) Chromatin structure in aging mouse liver. Gerontology 25:173-174.

17. Medvedev ZA, Medvedeva MN, Robson L (1978) Tissue specificity and age changes for the pattern of the $\mathrm{H} 1$ group of histones in chromatin from mouse tissues. Gerontology 24:286-292.

18. Tas S, Tam CF, Walford RL (1980) Disulfide bonds and the structure of the chromatin complex in relation to aging. Mech Ageing Dev 12: 65-80.

19. Uzunova K, Georgieva M, Miloshev G (2013) Saccharomyces cerevisiae linker histone-Hholp maintains chromatin loop organization during ageing. Oxid Med Cell Longev 2013: 437146.

20. Zhelabovskaya SM, Berdyshev GD (1972) Composition, template activity and thermostability of the liver chromatin in rats of various age. Exp Gerontol 7: 313-320.

21. Pieri C, Zs-Nagy I, Giuli C, Zs-Nagy V, Bertoni-Freddari C (1976) Agedependent increase of thermal stability of in situ chromatin of rat liver and its reversal after hepatectomy. Experientia 32: 891-893.

22. Przybilla J, Galle J, Rohlf T (2012) Is adult stem cell aging driven by conflicting modes of chromatin remodeling? Bioessays 34: 841-848.

23. Almagor M, Cole RD (1989) Changes in chromatin structure during the aging of cell cultures as revealed by differential scanning calorimetry. Biochemistry 28: 5688-5693.

24. O'Meara AR, Herrmann RL (1972) A modified mouse liver chromatin preparation displaying age-related differences in salt dissociation and template ability. Biochim Biophys Acta 269: 419-427.

25. Medvedev ZA, Medvedeva MN, Robson L (1979) Age-related changes of the pattern of non-histone chromatin proteins from rat and mouse liver chromatin. Gerontology 25: 219-227.

26. Grigor'eva AV, Iarygin VN (1985) Cytological analysis of the protein component of the nuclear chromatin in rat sympathetic neurocytes in postnatal ontogeny. I. The age-related changes in the histones detectable by ammoniacal silver and the matrix activity of the chromatin in rat sympathetic neurocytes. Tsiologia 27:186-190.

27. Jeanny JC, Gontcharoff M (1978) Electron-microscopy and scanning cytophotometry study of chromatin structure and distribution in cartilaginous cells nuclei of triturus-cristatus during aging. Biol Cell 32:233-243.

28. Ryan JM, Cristofalo VJ (1975) Chromatin template activity during aging in WI38 cells. Exp Cell Res 90: 456-458.

29. Stein GS, Wang PL, Adelman RC (1973) Age-dependent changes in the structure and function of mammalian chromatin. I. Variations in chromatin template activity. Exp Gerontol 8: 123-133.

30. Macieira-Coelho A, Puvion-Dutilleul F (1984) Evaluation of age-related chromatin changes by image-analysis. In vitro 20:282.

31. Moraes AS, Guaraldo AM, Mello ML (2007) Chromatin supraorganization and extensibility in mouse hepatocytes with development and aging. Cytometry A 71:28-37.

32. Hill BT (1976) Influenza of age on chromatin transcription in murine tissues using a heterologous and an homologous RNA polymerase. Gerontology 22: 111-123.

33. Weisman-Shomer P, Kaftory A, Fry M (1979) Replicative activity of isolated chromatin from proliferating and quiescent early passage and aging cultured mouse cells. J Cell Physiol 101: 219-227. 
Page 5 of 6

34. Silber JR, Fry M, Martin GM, Loeb LA (1985) Fidelity of DNA polymerases isolated from regenerating liver chromatin of aging Mus musculus. J Biol Chem 260: 1304-1310.

35. Mozzhukhina TG, Chabanny VN, Levitsky EL, Litoshenko AYa (1991) Age-related changes of supranucleosomal structures and DNAsynthesizing properties of rat liver chromatin. Gerontology 37: 181-186.

36. Modak SP, Gonet C, Ungerullmann C, Chappius M (1978) Chromatin structure in aging mouse-liver. Experientia 34:949.

37. Zongza V, Mathias AP (1979) The variation with age of the structure of chromatin in three cell types from rat liver. Biochem J 179: 291-298.

38. Chaurasia P, Mukherjee S, Thakur MK (1996) Age-related analysis of EcoRI generated satellite DNA-containing chromatin of rat liver. Biochem Mol Biol Int 40: 1261-1270.

39. Mahendra G, Gupta S, Kanungo MS (1999) Effect of 17beta estradiol and progesterone on the conformation of the chromatin of the liver of female Japanese quail during aging. Arch Gerontol Geriatr 28: 149-158.

40. Berkowitz EM, Sanborn AC, Vaughan DW (1983) Chromatin structure in neuronal and neuroglial cell nuclei as a function of age. J Neurochem 41: 516-523.

41. Thakur MK, Asaithambi A, Mukherjee S (1999) Sex-specific alterations in chromatin conformation of the brain of aging mouse. Mol Biol Rep 26: 239-247.

42. Gaubatz J, Ellis M, Chalkley R (1979) The structural organization of mouse chromatin as a function of age. Fed Proc 38: 1973-1978.

43. Hill BT, Whelan RD (1978) Studies on the degradation of ageing chromatin DNA by nuclear and cytoplasmic factors and deoxyribonucleases. Gerontology 24: 326-336.

44. Ghiraldini FG, Silva IS, Mello ML (2012) Polyploidy and chromatin remodeling in hepatocytes from insulin-dependent diabetic and normoglycemic aged mice. Cytometry A 81: 755-764.

45. Ishimi Y, Kojima M, Takeuchi F, Miyamoto T, Yamada M, et al. (1987) Changes in chromatin structure during aging of human skin fibroblasts. Exp Cell Res 169: 458-467.

46. Jedlicki A, Barros C, Salgado AM, Herrera E (1986) Effects of in vivo oocyte aging on sperm chromatin decondensation in the golden hamster. Gamete Res 14:347-354.

47. Manosalva I, González A (2010) Aging changes the chromatin configuration and histone methylation of mouse oocytes at germinal vesicle stage. Theriogenology 74: 1539-1547.

48. Zubkova EV, Wade M, Robaire B (2005) Changes in spermatozoal chromatin packaging and susceptibility to oxidative challenge during aging. Fertil Steril 84 Suppl 2: 1191-1198.

49. Zubkova EV, Robaire B (2006) Effects of ageing on spermatozoal chromatin and its sensitivity to in vivo and in vitro oxidative challenge in the Brown Norway rat. Hum Reprod 21: 2901-2910.

50. Wyrobek AJ, Eskenazi B, Young S, Arnheim N, Tiemann-Boege I, et al. (2006) Advancing age has differential effects on DNA damage, chromatin integrity, gene mutations, and aneuploidies in sperm. Proc Natl Acad Sci U S A 103: 9601-9606.

51. Nijs M, De Jonge C, Cox A, Janssen M, Bosmans E, et al. (2011) Correlation between male age, WHO sperm parameters, DNA fragmentation, chromatin packaging and outcome in assisted reproduction technology. Andrologia 43:174-179.

52. Myśliwski A, Myśliwska J, Kmieć Z (1977) Age-related changes in chromatin of liver cell nuclei of different ploidity. Histochemistry 52: 91-96.

53. Pantic I, Pantic S, Paunovic J (2012) Aging increases nuclear chromatin entropy of erythroid precursor cells in mice spleen hematopoietic tissue. Microsc Microanal 18: 1054-1059.

54. Adams PD (2007) Remodeling of chromatin structure in senescent cells and its potential impact on tumor suppression and aging. Gene 397: 84-93.

55. Sedivy JM, Banumathy G, Adams PD (2008) Aging by epigenetics--a consequence of chromatin damage? Exp Cell Res 314: 1909-1917.
56. Cutler RG (1975) Age-dependent accumulation of DNA adducts in chromatin. Gerontologist 15:33.

57. Gupta S, Pathak RU, Kanungo MS (2006) DNA methylation induced changes in chromatin conformation of the promoter of the vitellogenin II gene of Japanese quail during aging. Gene 377: 159-168.

58. Rakyan VK, Down TA, Maslau S, Andrew T, Yang TP, et al. (2010) Human aging-associated DNA hypermethylation occurs preferentially at bivalent chromatin domains. Genome Res 20: 434-439.

59. Watson CT, Disanto G, Sandve GK, Breden F, Giovannoni G, et al. (2012) Age-associated hyper-methylated regions in the human brain overlap with bivalent chromatin domains. PLoS One 7: e43840.

60. Oh JH, Gertych A, Tajbakhsh J (2013) Nuclear DNA methylation and chromatin condensation phenotypes are distinct between normally proliferating/aging, rapidly growing/immortal, and senescent cells. Oncotarget 4:474-493.

61. Kanungo MS, Thakur MK (1979) Modulation of acetylation of histones and transcription of chromatin by butyric acid and 17beta-estradiol in the brain of rats of various ages. Biochem Biophys Res Commun 87: 266-271.

62. Russanova VR, Hirai TH, Tchernov AV, Howard BH (2004) Mapping development-related and age-related chromatin remodeling by a high throughput ChIP-HPLC approach. J Gerontol A Biol Sci Med Sci 59: 1234-1243.

63. Lindner H, Sarg B, Grunicke H, Helliger W (1999) Age-dependent deamidation of $\mathrm{H1}(0)$ histones in chromatin of mammalian tissues. J Cancer Res Clin Oncol 125: 182-186.

64. Rodrigues HF, Souza TA, Ghiraldini FG, Mello ML, Moraes AS (2014) Increased age is associated with epigenetic and structural changes in chromatin from neuronal nuclei. J Cell Biochem 115: 659-665.

65. Oberdoerffer P, Michan S, McVay M, Mostoslavsky R, Vann J, et al. (2008) SIRT1 redistribution on chromatin promotes genomic stability but alters gene expression during aging. Cell 135: 907-918.

66. Pegoraro G, Kubben N, Wickert U, Göhler H, Hoffmann K, et al. (2009) Ageing-related chromatin defects through loss of the NURD complex. Nat Cell Biol 11: 1261-1267.

67. Vijg J, Suh Y (2006) Ageing: chromatin unbound. Nature 440: 874-875.

68. Massudi H, Grant R, Braidy N, Guest J, Farnsworth B, et al. (2012) Ageassociated changes in oxidative stress and NAD+ metabolism in human tissue. PLoS One 7: e42357.

69. Campisi J (2000) Aging, chromatin, and food restriction--connecting the dots. Science 289: 2062-2063.

70. Jiang N, Du G, Tobias E, Wood JG, Whitaker R, et al. (2013) Dietary and genetic effects on age-related loss of gene silencing reveal epigenetic plasticity of chromatin repression during aging. Aging (Albany NY) 5 : 813-824.

71. Guarente L (2000) Sir2 links chromatin silencing, metabolism, and aging. Genes Dev 14: 1021-1026.

72. Wood JG, Hillenmeyer S, Lawrence C, Chang C, Hosier S, et al. (2010) Chromatin remodeling in the aging genome of Drosophila. Aging Cell 9: 971-978.

73. Manosalva I, González A (2010) Aging changes the chromatin configuration and histone methylation of mouse oocytes at germinal vesicle stage. Theriogenology 74: 1539-1547.

74. Abrass CK, Hansen K, Popov V, Denisenko O (2011) Alterations in chromatin are associated with increases in collagen III expression in aging nephropathy. Am J Physiol Renal Physiol 300: F531-539.

75. Kanungo MS, Thakur MK (1979) Phosphorylation and acetylation of nonhistone chromosomal proteins of the brain of rats of various ages and their modulation by calcium and estradiol. Biochem Biophys Res Commun 86: 14-19.

76. Liu L, Cheung TH, Charville GW, Hurgo BM, Leavitt T, et al. (2013) Chromatin modifications as determinants of muscle stem cell quiescence and chronological aging. Cell Rep 4: 189-204. 
77. Schuler N, Rübe CE (2013) Accumulation of DNA damage-induced chromatin alterations in tissue-specific stem cells: the driving force of aging? PLoS One 8: e63932.

78. McCord RA, Broccoli D (2008) Telomeric chromatin: roles in aging, cancer and hereditary disease. Mutat Res 647: 86-93.
79. Ye J, Wu Y, Gilson E (2010) Dynamics of telomeric chromatin at the crossroads of aging and cancer. Essays Biochem 48: 147-164.

80. Pegoraro G, Misteli T (2009) The central role of chromatin maintenance in aging. Aging (Albany NY) 1: 1017-1022. 